\title{
Effect of Nb doping on structural, optical and photocatalytic properties of flame-made $\mathrm{TiO}_{2}$ nanopowder
}

\author{
Katarzyna A. Michalow • Dorota Flak • Andre Heel • \\ Magdalena Parlinska-Wojtan • Mieczyslaw Rekas • \\ Thomas Graule
}

Received: 21 October 2011 / Accepted: 24 April 2012

(C) Springer-Verlag 2012

\begin{abstract}
TiO}_{2}: \mathrm{Nb}$ nanopowders within a dopant concentration in the range of $0.1-15$ at.\% were prepared by onestep flame spray synthesis. Effect of niobium doping on structural, optical and photocatalytic properties of titanium dioxide nanopowders was studied. Morphology and structure were investigated by means of Brunauer-Emmett-Teller isotherm, X-ray diffraction and transmission electron microscopy. Diffuse reflectance and the resulting band gap energy were determined by diffuse reflectance spectroscopy.
\end{abstract}

Responsible editor: Philippe Garrigues

K. A. Michalow $(\bowtie) \cdot$ D. Flak $\cdot$ T. Graule

Laboratory for High Performance Ceramics, Empa Swiss Federal

Laboratories for Materials Science and Technology,

Ueberlandstrasse 129

8600 Duebendorf, Switzerland

e-mail: katarzyna.michalow@empa.ch

\section{A. Heel}

Marketing, Knowledge \& Technology Transfer, Empa Swiss

Federal Laboratories for Materials Science and Technology,

Ueberlandstrasse 129 ,

8600 Duebendorf, Switzerland

M. Parlinska-Wojtan

Electron Microscopy Center, Empa Swiss Federal Laboratories

for Materials Science and Technology,

Ueberlandstrasse 129,

8600 Duebendorf, Switzerland

D. Flak $\cdot$ M. Rekas

Faculty of Material Science and Ceramics,

AGH University of Science and Technology,

al. Mickiewicza 30,

30-059 Krakow, Poland

M. Parlinska-Wojtan

Institute of Nanotechnology, University of Rzeszow,

ul. Rejtana 16a,

35-959 Rzeszow, Poland
Photocatalytic activity of the investigated nanopowders was revised for the photodecomposition of methylene blue (MB), methyl orange (MO) and 4-chlorophenol under UVA and VIS light irradiation. Commercial $\mathrm{TiO}_{2}-\mathrm{P} 25$ nanopowder was used as a reference. The specific surface area of the powders was ranging from $42.9 \mathrm{~m}^{2} / g$ for $\mathrm{TiO}_{2}: 0.1$ at.\% $\mathrm{Nb}$ to $90.0 \mathrm{~m}^{2} / \mathrm{g}$ for $\mathrm{TiO}_{2}: 15$ at. $\% \mathrm{Nb}$. $\mathrm{TiO}_{2}: \mathrm{Nb}$ particles were nanosized, spherically shaped and polycrystalline. Anatase was the predominant phase in all samples. The anatase-related transition was at $3.31 \mathrm{eV}$ and rutile-related one at $3.14 \mathrm{eV}$. $\mathrm{TiO}_{2}: \mathrm{Nb}$ nanopowders exhibited additional absorption in the visible range. In comparison to $\mathrm{TiO}_{2}-\mathrm{P} 25$, improved photocatalytic activity of $\mathrm{TiO}_{2}: \mathrm{Nb}$ was observed for the degradation of $\mathrm{MB}$ and $\mathrm{MO}$ under both UVA and VIS irradiation, where low doping level $(\mathrm{Nb}<1$ at.\%) was the most effective. Niobium doping affected structural, optical and photocatalytic properties of $\mathrm{TiO}_{2}$. Low dopant level enhanced photocatalytic performance under UVA and VIS irradiation. Therefore, $\mathrm{TiO}_{2}: \mathrm{Nb}(\mathrm{Nb}<1$ at.\%) can be proposed as an efficient selective solar light photocatalyst.

Keywords $\mathrm{TiO}_{2} \cdot$ Photocatalysis $\cdot$ Visible light $\cdot$ Doping . Niobium $\cdot$ Nanoparticles $\cdot$ Methylene blue $\cdot$ Methyl orange . 4-Chlorophenol

\section{Introduction}

Nowadays, domestically and industrially generated waste is an urgent concern, which has to be solved without emission of additional pollutants during waste utilization. Photocatalysis can be a solution. However, there is still a need for an efficient, stable and nontoxic material, which can be activated by solar energy. $\mathrm{TiO}_{2}$ is still the most common photocatalyst on the market even though it is active only under 
UV irradiation and recombination process is additionally hampering its performance. Therefore, $\mathrm{TiO}_{2}$ shows poor photocatalytic efficiency under solar irradiation (Fujishima and Zhang 2006; Radecka et al. 2006).

To enhance its efficiency, the light absorption towards the visible range has to be extended, and recombination of the charges has to be minimized. One of the interesting properties of $\mathrm{TiO}_{2}$ is its susceptibility for structure modification by doping. The cationic sublattice can be doped with either donor-type ions such as $\mathrm{W}^{6+}, \mathrm{Mo}^{6+}$ or $\mathrm{Nb}^{5+}$ (Akurati et al. 2008; Cui et al. 1995; Kubacka et al. 2009; Mattsson et al. 2006; Michalow et al. 2008; Michalow et al. 2009a) or acceptor-type ions such as $\mathrm{Cr}^{3+}$ or $\mathrm{Fe}^{3+}$ (Borgarello et al. 1982; Radecka et al. 2010; Trenczek-Zajac et al. 2009). The anionic sublattice of $\mathrm{TiO}_{2}$ can be doped with $\mathrm{N}, \mathrm{S}$ or $\mathrm{F}$ (Asahi et al. 2001; Chen and Mao 2007; Michalow et al. 2009b). However, anionic doping suffers from thermal instability and subsequent ageing problems. Therefore, doping of the cationic sublattice is more reasonable if outdoor applications are considered.

Among donor type of dopants, niobium as a pentavalent ion $\left(\mathrm{Nb}^{5+}\right)$ with a similar ionic radius $(0.69 \AA)$ to that of $\mathrm{Ti}^{4+}$ $(0.64 \AA)$ seems to be optimal (Shannon 1976). In addition, $\mathrm{Nb}$ as $\mathrm{Nb}_{2} \mathrm{O}_{5}$ can be isotropically dissolved in $\mathrm{TiO}_{2}$, and a solid solution can be formed for a wide concentration range. Modification by transition metal ion doping is particularly of interest to increase the electrical conductivity and to decrease recombination losses. Finklea (1988) reported a charge carrier density on a level of $10^{19} \mathrm{~cm}^{-3}$ for $\mathrm{TiO}_{2}: 0.1$ at. $\% \mathrm{Nb}$ and location of a unionized donor $\mathrm{Nb}^{4+}$ at $0.12 \mathrm{eV}$ below the conduction band, which can act as shallow trapping centres. There are also some contradictions among researchers regarding effect of $\mathrm{Nb}$ on the optical properties. A red shift of $\sim 0.15 \mathrm{eV}$ of the fundamental absorption edge was reported for low doping at the level of 0.5 at. $\% \mathrm{Nb}$ (Wang et al. 1995) and the same effect for high dopant concentration of about 20 at.\% Nb (Mattsson et al. 2006). On the other hand, Gautron et al. (1983) reported no band shift for $\mathrm{TiO}_{2}-\mathrm{NbO}_{2}$ solid-state solution with 20 at. $\% \mathrm{Nb}$. Doping by $\mathrm{Nb}$ can create stronger acid sites on $\mathrm{TiO}_{2}$ surface that contributes to the enhancement of catalytic activity and selectivity for various catalytic processes including photocatalytic decomposition (Okazaki and Okuyama 1983; Cui et al. 1995; Akurati et al. 2008). $\mathrm{TiO}_{2}: \mathrm{Nb}$ materials are already used for a great variety of applications, e.g. as a gas sensor (Atashbar et al. 1998; Sharma et al. 1998; Carotta et al. 1999; Ferroni et al. 2000; Anukunprasert et al. 2005; Ruiz et al. 2003; Teleki et al. 2008; Traversa et al. 2001; Zakrzewska et al. 1997), as anodes in photoelectrochemical cells for water splitting (Trenczek-Zajac et al. 2007; Wang et al. 1995), as electrodes for dye-sensitized solar cells (Tsvetkov et al. 2011a, b) and seems to be wellperforming material for photocatalytic decomposition of organic pollutants under solar irradiation (Mattsson et al. 2006).
Another way to improve a photocatalyst performance is a downscaling of the particle dimension. With nano-size, new physical and chemical properties emerge as well as an increased reactive surface leads to enhanced light absorption and water/hydroxyl groups/pollutant adsorption. It is also known that highly crystalline nano-anatase particles are the most suitable for a photocatalytic application (Almquist and Biswas 2002; Chen and Mao 2007; Sclafani and Herrmann 1996).

The present study reports on the synthesis of $\mathrm{TiO}_{2}: \mathrm{Nb}$ anatase-phase nanoparticles by liquid-fed one-step flame spray synthesis (FSS). Employing FSS with acetylene as a flame fuel guaranteed a high temperature $(\sim 3,300 \mathrm{~K})$. Therefore, well-crystalline nanoparticles were obtained with high production rate with no need for posttreatment. For as-prepared $\mathrm{TiO}_{2}: \mathrm{Nb}$ nanoparticles, an effect of $\mathrm{Nb}^{5+}$ dopant on the structural and optical properties of $\mathrm{TiO}_{2}$ was investigated. The major aim of such a material composition is to increase the spectral sensitivity of the photocatalyst towards the visible light range, which composes the largest part of the solar irradiation and therefore the development of an efficient and pollution-free waterwaste remediation system.

\section{Experimental}

Synthesis of $\mathrm{Nb}$-doped $\mathrm{TiO}_{2}$ nanoparticles

$\mathrm{TiO}_{2}: \mathrm{Nb}$ nanopowders with a dopant concentration in the range of $0-15$ at.\% were prepared by a one-step FSS using titanium tetraisopropoxide (TTIP; $\mathrm{Ti}\left(\mathrm{C}_{3} \mathrm{H}_{7} \mathrm{O}\right)_{4} 99 \%$, VWR International) and a solution of niobium chloride $\left(\mathrm{NbCl}_{5}\right.$; $99 \%$, ABCR) in ethanol ( $99 \%$, Sigma Aldrich). Details of the flame spray setup are reported elsewhere (Akurati et al. 2008; Michalow et al. 2008). The required composition of the produced particles was obtained by adjusting a proper ratio of the feed flow rates of the $\mathrm{TiO}_{2}$ precursor TTIP $\left(\mathrm{FR}_{\mathrm{TTIP}}\right)$ and the dopant precursor $\left(\mathrm{FR}_{\mathrm{D}}\right)$. $\mathrm{TiO}_{2}$ precursor and dopant precursor were fed individually by using two syringe pumps. The process control parameter $\lambda_{\mathrm{FSS}}$ (oxygen-to-fuel ratio in the FSS combustion process) was kept constant for all syntheses. The total flow rate of the precursor mixture was in the range of $0.135-0.155 \mathrm{~cm}^{3} \mathrm{~s}^{-1}$. The precursors were mixed prior to the nozzle and then atomized by a gas-assisted external mixing nozzle by oxygen (flow rate of dispersion gas was $583 \mathrm{~cm}^{3} \mathrm{~s}^{-1}$ ). This combustible aerosol was ignited by six acetylene-oxygen flamelets (flow rates, $\mathrm{C}_{2} \mathrm{H}_{2}=217 \mathrm{~cm}^{3} \mathrm{~s}^{-1}, \mathrm{O}_{2}=283 \mathrm{~cm}^{3} \mathrm{~s}^{-1}$ ). The produced particles were collected in a bag house filter system, and representative samples (1-2 g) were collected on glass fibre filters (GF/A 150, Whatman) via a bypass using vacuum pumps. 
Characterization of $\mathrm{Nb}$-doped $\mathrm{TiO}_{2}$

The specific surface area (SSA) of as-prepared powders was determined from a five-point $\mathrm{N}_{2}$ adsorption isotherm obtained from Brunauer-Emmett-Teller (BET) measurements using a Beckman Coulter SA3100. Prior to analysis, powder samples were dried at $180^{\circ} \mathrm{C}$ for $120 \mathrm{~min}$ in nitrogen atmosphere to remove physisorbed water from the surface.

$\mathrm{X}$-ray diffraction (XRD) analysis was performed with a Philips PANalytical X'Pert Pro MPD diffractometer using $\mathrm{Cu}$ $\mathrm{K} \alpha$ filtered radiation over a $2 \theta$ range from $10^{\circ}$ to $80^{\circ}$. The XRD results were used to determine the phase composition and the resulting anatase/rutile volume ratio. Phase identification was carried out using the Inorganic Crystal Structure Database (ICSD).

Particle size, shape and morphology of flame-made $\mathrm{TiO}_{2}: \mathrm{Nb}$ nanopowders were investigated by scanning and transmission electron microscopy (STEM-TEM). TEM images were recorded with a high-resolution and analytical STEM-TEM JEOL 2200FS equipped with an omega filter for energy-filtered imaging. The powder samples for TEM measurements were deposited onto carbon-coated copper grids (Plano GmbH).

The band gap energy ( $E_{\mathrm{g}}$, energy of the fundamental optical transitions from the valence band to the conduction band) was derived from optical diffuse reflectance spectra $R$ $(\lambda)$. Spectrophotometric measurements were performed with a Lambda 19 Perkin-Elmer double-beam spectrophotometer, equipped with a $150 \mathrm{~mm}$ integrating sphere and used to measure the spectral dependence of total and diffuse reflectance in the wavelength range from 250 to $2,500 \mathrm{~nm}$.

\section{Photocatalytic experiments}

Three different aqueous (deionized water with $\mathrm{pH}=5.5$ ) solutions $5.13 \times 10^{-5} \mathrm{M}$ methylene blue (MB), $5.19 \times 10^{-5} \mathrm{M}$ methyl orange (MO) and $1.00 \times 10^{-3} \mathrm{M}$ 4-chlorophenol (4$\mathrm{CP})$ were prepared for photoactivity evaluation experiments. The $\mathrm{pH}$ of MB solution was 5.5, and the $\mathrm{pH}$ of MO solution was 4.5 , and no adjustment of $\mathrm{pH}$ was done. The $\mathrm{pH}$ of 4-CP solution was adjusted with $1 \mathrm{M}$ perchloric acid to final value of $\mathrm{pH}=2$, following Mills et al. (1993). The powder concentration was kept constant at $0.4 \mathrm{mg} / \mathrm{cm}^{3}$. The reaction suspension of the powder in the pollutant solution was subjected to an ultrasound treatment for $10 \mathrm{~min}$. The photocatalytic experiments were carried out in a photochemical photoreactor Lidam. The details of the setup are given elsewhere (Mills et al. 1993; Mills and Morris 1993). In brief, the photochemical irradiation system comprised two half cylinders, each of them contained six Sylvania Blacklight Blue F8W/BLB T5 $\left(\lambda_{\text {max. }}=355-360 \mathrm{~nm}\right)$ for UVA irradiation, LCD Lightening Inc. M2-65-01 Hg lamps $\left(\lambda_{\text {max. }}=435 \mathrm{~nm}\right)$ for the visible light irradiation. The reaction vessel was a double-walled $125 \mathrm{~cm}^{3}$ quartz Drechsel bottle fitted with a rubber septum through which the samples were extracted. Thermostated water $\left(30^{\circ} \mathrm{C}\right)$ was pumped continuously through the outer jacket of the reaction vessel during the experiments. A sample of the photocatalyst was dispersed in a reaction solution and was filled into the inner part of the reaction vessel, magnetically stirred (300 rpm) and continuously purged with air $(110 \mathrm{ml} / \mathrm{min})$ from the central line over the irradiation period. Extracted samples were filtered through membrane filters $\left(0.2 \mu \mathrm{m}\right.$ Nylon, Roth Rotilabo $\left.{ }^{\circledR}\right)$ into PMMA cuvettes (Roth). Samples were extracted at fixed time intervals and characterized by a UV-VIS Varian Cary 50 SCAN spectrophotometer. Calibration of the absorbance at $664 \mathrm{~nm}$ against $\mathrm{MB}$ concentration, at $464 \mathrm{~nm}$ against MO concentration and $280 \mathrm{~nm}$ against 4-CP concentration (Lambert-Beer Law) was carried out for the determination of the photocatalytic activity (PCA), and the concentration was determined from the peak intensity.

\section{Results and discussion}

Structural properties of $\mathrm{TiO}_{2}: \mathrm{Nb}$ nanopowders

The specific surface area of as-synthesized powders varied as a function of the doping amount from $42.9 \mathrm{~m}^{2} / \mathrm{g}$ for $\mathrm{TiO}_{2}: 0.1$ at. $\% \mathrm{Nb}$ to $90 \mathrm{~m}^{2} / \mathrm{g}$ for $\mathrm{TiO}_{2}: 15$ at. $\% \mathrm{Nb}$ doped (Table 1). The increase of SSA with higher $\mathrm{Nb}$ level is determined by the synthesis parameters. As it can be seen in Fig. 1, there is a correlation between the precursor mole number $\left(n_{\text {prec }}\right)$ and SSA. Namely, a higher precursor mole number per time unit results in lower SSA because a higher supersaturation in the flame is reached from which bigger particles result. The total feed flow rate $\left(\mathrm{FR}_{\text {Total }}\right)$ was kept constant during synthesis routine. In order to increase $\mathrm{Nb}$ concentration in $\mathrm{TiO}_{2}$ nanoparticles, feed flow rate of $\mathrm{Nb}$ precursor was increased and feed flow rate of main precursor titanium tetraisopropoxide TTIP ( $\mathrm{FR}_{\mathrm{TTIP}}$ ) decreased. This resulted in a simultaneous increase of the $\mathrm{Nb}$ level in $\mathrm{TiO}_{2}$ and SSA of the powder.

The morphology of $\mathrm{TiO}_{2}: \mathrm{Nb}$ nanopowders was observed by TEM. The TEM images (Fig. 2) showed that flame-made $\mathrm{TiO}_{2}: \mathrm{Nb}$ nanopowders consist of nanosized, spherically shaped and crystalline particles. The size distribution of the $\mathrm{TiO}_{2}$-based particles was the broadest for powders containing 0.1 at. $\% \mathrm{Nb}$ as it was covering a particle size from 10 up to $90 \mathrm{~nm}$, with an average size of $40 \mathrm{~nm}$ (Fig. 2a). The size of $\mathrm{TiO}_{2}$ particles with 5 at.\% $\mathrm{Nb}$ varied between 5 and $90 \mathrm{~nm}$; however, it can be clearly seen from Fig. $2 \mathrm{c}$ that the average particle size is smaller $(28 \mathrm{~nm})$ than for particles with a lower $\mathrm{Nb}$ content (Fig. 2a). For a 15 at.\% Nb level, the particle size remained below $30 \mathrm{~nm}$ (average size, $14 \mathrm{~nm}$ ), and no large particles were observed (Fig. 2e). 
Table 1 Structural parameters of $\mathrm{TiO}_{2}: \mathrm{Nb}$ and $\mathrm{TiO}_{2}-\mathrm{P} 25$ nanopowders

${ }^{\mathrm{a}} d_{\mathrm{XRD}, \mathrm{R}}=35 \mathrm{~nm}$

${ }^{\mathrm{b}} d_{\mathrm{BET}}$ calculated with assumption of $3 \mathrm{wt} \%$ of rutile

\begin{tabular}{lccccc}
\hline Sample name & $\mathrm{SSA} / \mathrm{m}^{2} \mathrm{~g}^{-1}$ & $d_{\mathrm{BET}} / \mathrm{nm}$ & $\mathrm{wt} \%$ rutile & $d_{\text {XRD, A }} / \mathrm{nm}$ & $d_{\mathrm{TEM}} / \mathrm{nm}$ \\
\hline $\mathrm{TiO}_{2}-\mathrm{P} 25^{\mathrm{a}}$ & 49.1 & 30.9 & 16.9 & 21 & - \\
$\mathrm{TiO}_{2}: 0.1$ at.\% Nb & 42.9 & $35.8^{\mathrm{b}}$ & - & - & 39.9 \\
$\mathrm{TiO}_{2}: 0.5$ at.\% Nb & 47.7 & 35.8 & 2.8 & 31.0 & - \\
$\mathrm{TiO}_{2}: 1$ at.\% $\mathrm{Nb}$ & 52.0 & 32.2 & 3.3 & 33.6 & - \\
$\mathrm{TiO}_{2}: 5$ at. $\% \mathrm{Nb}$ & 66.7 & 29.3 & 3.5 & 22.3 & 27.6 \\
$\mathrm{TiO}_{2}: 10$ at.\% Nb & 82.0 & 22.7 & 2.5 & 13.4 & - \\
$\mathrm{TiO}_{2}: 15$ at. $\% \mathrm{Nb}$ & 90.0 & $18.4^{\mathrm{b}}$ & - & - & 14.5 \\
\hline
\end{tabular}

The selected area electron diffraction (SAED) pattern taken for the $\mathrm{TiO}_{2}$ particles with 0.1 at. $\%$ of $\mathrm{Nb}$ consists mainly of spots, which are generated by the largest particles (inset of Fig. 2b). No preferential orientation of the particles could be observed. Conversely, the SAED pattern of the particles containing 15 at. $\% \mathrm{Nb}$ is composed of rings with rare distinct spots, confirming the reduction of the particle size and their random distribution.

The diffraction patterns consisting of sharp rings with spots and the high-resolution images confirmed the crystalline character of the powders. The high-resolution TEM images (HRTEM), Fig. 2b, d, and f, clearly show differently oriented lattice fringes for the different particles. Independently on their size, the particles were not single crystalline, but contained grain boundaries and hence multiple grains with different lattice orientations within a single particle. The surface layer of the particles seemed to have an amorphous character and some of the smallest particles, with sizes below $10 \mathrm{~nm}$ seemed to be amorphous (Fig. 2f). The energy-filtered mapping (EFTEM), inset in Fig. 2c, e, confirmed the presence and of $\mathrm{Ti}, \mathrm{O}$ and $\mathrm{Nb}$ in the analysed particles. The distribution of these three elements in the particles was uniform up to 5 at. $\% \mathrm{Nb}$. In the case of particles with 15 at. $\% \mathrm{Nb}$, also high concentrations of $\mathrm{Nb}$

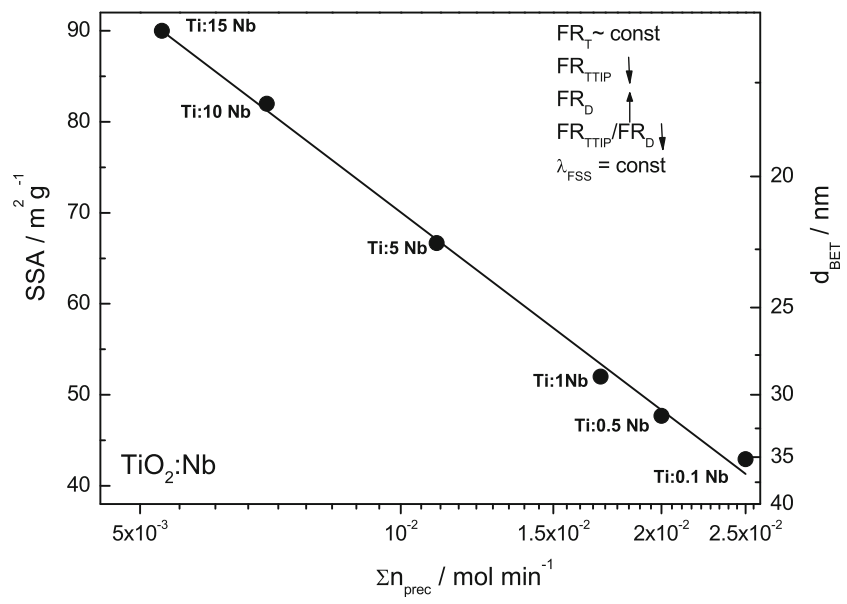

Fig. 1 The specific surface area (SSA) and the particle size $\left(d_{\mathrm{BET}}\right)$ of $\mathrm{TiO}_{2}: \mathrm{Nb}$ nanopowders as a function of total precursor concentration on the surface were detected (inset in Fig. 2e, dominating purple colour, which indicates presence of $\mathrm{Nb}$ ). This effect was also confirmed by XRD results (Fig. 3). Samples with higher level of $\mathrm{Nb}$ doping are not homogenous, and traces of additional phase can be detected. Presence of such Nb-rich zones in the photocatalytic material can negatively affect photoactivity through an enhancement of the recombination process.

Effect of niobium on $\mathrm{TiO}_{2}$ crystallinity and phase composition was investigated by XRD measurements (Fig. 3). The intensities of the anatase reflection at $2 \theta=25.4^{\circ}$ and the rutile reflection at $2 \theta=27.5^{\circ}$ were analysed, and the percentage of rutile in the samples was determined using the following equation, Eq. 1 (Spurr and Myers 1957).

$\chi=\left(1+0.8 \frac{I_{\mathrm{A}}}{I_{\mathrm{R}}}\right)^{-1}$

Where, $\chi$ is the weight fraction of rutile in the powder, $I_{\mathrm{A}}$ and $I_{\mathrm{R}}$ are peak intensities of anatase and rutile phase, respectively.

FSS-made nanopowders are well crystalline as was expected from elaboration procedure since the flame spray synthesis is a one-step process, which allows obtaining crystalline powders owing to high temperature in the flame (Akurati et al. 2008). XRD patterns of the here presented FSS-made powders show that as-prepared nanopowders consist mainly of anatase phase (96-98 wt\%), which is the desired phase for the photocatalytic application. Besides anatase, rutile reflections can be observed as a second phase. Additional niobium oxide phase was formed at about 5 at.\% of $\mathrm{Nb}$ doping, which can be seen as reflections at $2 \theta=28.6^{\circ}, 2 \theta=33.0^{\circ}$ and $2 \theta=14.5^{\circ}$. These reflections are probably attributed to monoclinic $\mathrm{Nb}_{2} \mathrm{O}_{5}$, the most common and stable niobium oxide. A left shift of XRD pattern follows increasing level of niobium, which indicates an enlargement of unit cell (inset in Fig. 3). It originates from the value of ion radius of $\mathrm{Nb}^{5+}(0.69 \AA)$, which is slightly bigger than ion radius of $\mathrm{Ti}^{4+}$ (0.64 ̊) (Shannon 1976). Additionally, peak broadening was observed for powders with higher $\mathrm{Nb}$ level due to the smaller particle size. 
Fig. 2 TEM (a, c, e) and HRTEM (b, d, f) images of $\mathrm{TiO}_{2}: \mathrm{Nb}$ nanopowders: $\mathbf{a}-\mathbf{b}$ $\mathrm{TiO}_{2}: 0.1$ at. $\% \mathrm{Nb}, \mathbf{c}-\mathbf{d}$ $\mathrm{TiO}_{2}: 5$ at.\% $\mathrm{Nb}, \mathbf{e}-\mathbf{f}$ $\mathrm{TiO}_{2}: 15$ at. $\% \mathrm{Nb}$. Insets in $\mathbf{b}$ and $\mathbf{f}$ SAED patterns and insets in $\mathbf{c}$ and $\mathbf{e}$ EFTEM map of $\mathrm{Ti}$ (blue), O (yellow) and $\mathrm{Nb}$ (purple)
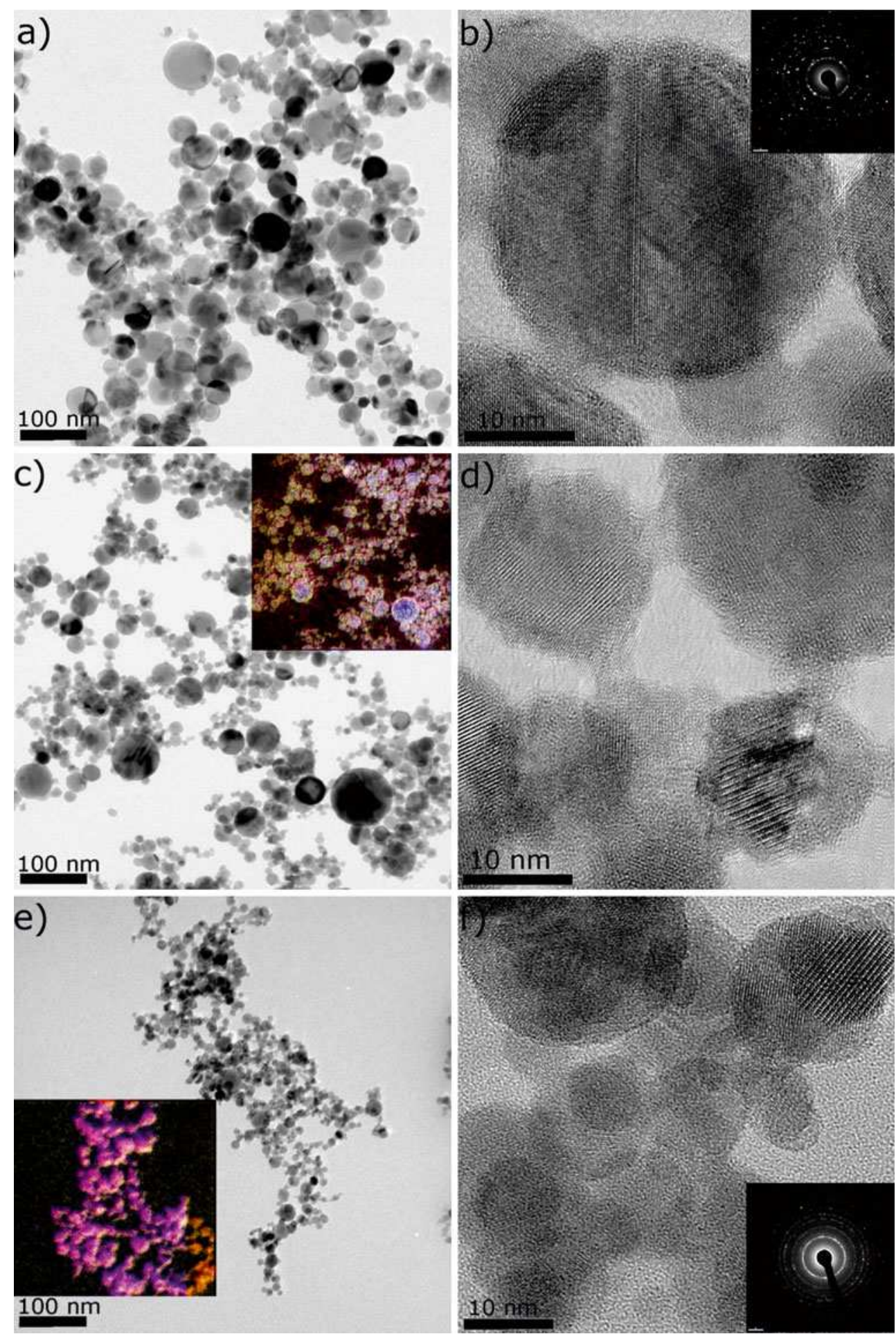

Anukunprasert et al. (2005) established that phase modification for $\mathrm{TiO}_{2}: \mathrm{Nb}$ nanopowders can be observed when $\mathrm{TiO}_{2}$ is doped with more than $3 \mathrm{~mol} \% \mathrm{Nb}$. Three to five mole percent of $\mathrm{Nb}$ hinders the anatase to rutile transformations, and only anatase polymorph was observed. Trenczek-Zajac et al. $(2006,2007)$ observed that samples containing more than 10 at. $\%$ of $\mathrm{Nb}$ are not homogenous, and traces of an additional titanium niobate phase were detected for samples with 15 at.\%
$\mathrm{Nb}$. Zaitsev et al. (2000) reported that the solubility limit of $\mathrm{Nb}$ was more than $5 \mathrm{~mol} \%$ in anatase, whereas Traversa et al. (2001) report up to 5 at.\% and Ruiz et al. (2003) of about 10 at.\% of $\mathrm{Nb}$ in anatase. Sheppard et al. (2006) found no evidence of another phase than anatase up to $40 \mathrm{at} . \% \mathrm{of} \mathrm{Nb}$. Tsvetkov et al. (2011b) showed that increase of $\mathrm{Nb}$ concentration resulted in decrease of rutile phase and for $\mathrm{TiO}_{2}: 3 \mathrm{~mol} \%$ $\mathrm{Nb}$ only anatase phase was detected. Kubacka et al. (2009) 


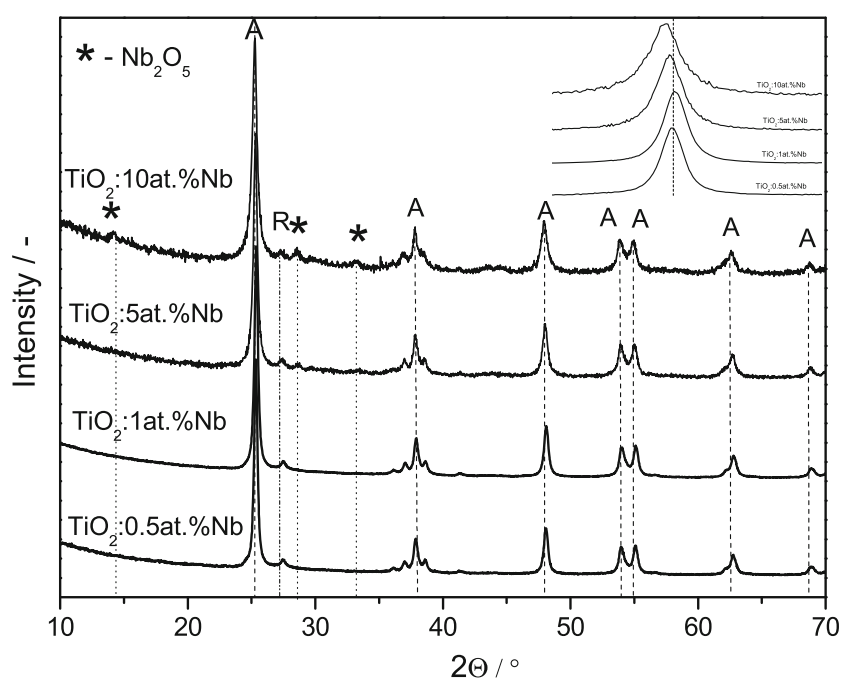

Fig. 3 XRD pattern of $\mathrm{TiO}_{2}$ : $\mathrm{Nb}$ with increasing level of doping; inset shows enlargement at $2 \theta=25.4^{\circ}$

obtained $\mathrm{TiO}_{2}$ doped with 9.7 and 20.2 at.\% $\mathrm{Nb}$ and observed that $\mathrm{Nb}$ displays a solubility limit, which can be seen as $\mathrm{Nb}$-rich local zones and arrangements within the anatase. Such a discrepancy among results reported in the literature can be related to a variety of used synthesis methods. Therefore, it can be assumed that niobium substitutes titanium in the crystal lattice up to a certain level of $\mathrm{Nb}$ doping, which seems to be strongly dependent on the material preparation technique. It seems difficult to establish the solubility limit of $\mathrm{Nb}$ in anatase since anatase-to-rutile transformation phase occurs at $973-1,173 \mathrm{~K}$ and the conditions of the thermodynamic equilibrium are not defined (Sheppard et al. 2006). Uncertainty in the identification of the additional phase next to anatase and rutile can be connected with the presence of some variations in the determination of exact position of the peak, arising from the hindered alignment during profile fitting. Nevertheless, there are few reports on $\mathrm{TiO}_{2}: \mathrm{Nb}$ claiming a presence of traces of niobium species, such as $\mathrm{NbO}_{2}$ or $\mathrm{Nb}_{2} \mathrm{O}_{5}$ (Zaitsev et al. 2000; Ruiz et al. 2003), with indication on the report of Teleki at al. (2008) on presence of $\mathrm{Nb}_{2} \mathrm{O}_{5}$ in FSS-made $\mathrm{TiO}_{2}: 10$ at. $\% \mathrm{Nb}$ nanopowder.

From the results obtained by XRD and BET measurements, particle size was calculated according to the following equation (Eq. 2):

$d_{\mathrm{BET}}=\frac{6,000}{\left(V_{\mathrm{A}} \times \rho_{\mathrm{A}}+V_{\mathrm{R}} \times \rho_{\mathrm{R}}+V_{\mathrm{Nb}} \times \rho_{\mathrm{Nb}}\right) \times \mathrm{SSA}}$

where, $V_{\mathrm{A}}, V_{\mathrm{R}}, V_{\mathrm{Nb}}$ and $\rho_{\mathrm{A}}, \rho_{\mathrm{R}}, \rho_{\mathrm{Nb}}$ are the volume fractions determined from the XRD patterns and the densities of anatase$\mathrm{TiO}_{2}$, rutile- $\mathrm{TiO}_{2}$ and $\mathrm{Nb}_{2} \mathrm{O}_{5}$, respectively $\left(\rho_{\mathrm{A}}=3.84 \mathrm{~g} / \mathrm{cm}^{3}\right.$, $\rho_{\mathrm{R}}=4.25 \mathrm{~g} / \mathrm{cm}^{3}$ and $\rho_{\mathrm{Nb}}=4.47 \mathrm{~g} / \mathrm{cm}^{3}$ ). Values of density were taken after ICSD data files. The average mean crystallite size of anatase was calculated from Scherrer's equation (Eq. 3)
(Ogawa et al. 1981) using the full-width-at-half-maximum value of the anatase diffraction peak:

$L=\frac{K \times \lambda}{(\beta \times \cos \theta)}=d_{\mathrm{XRD}}$

where, $L$ is the crystallite size, $\lambda$ is the wavelength of the $\mathrm{X}$-ray radiation $(\mathrm{Cu} \mathrm{K} \alpha 1.540598 \AA), K$ is 0.89 and $\beta$ is the line broadening at the half-maximum intensity after subtraction of equipment broadening. The average crystallite size was in the range of 13.4 to $35.0 \mathrm{~nm}$. According to Almquist and Biswas (2002), such grain sizes are the most suitable for photocatalytic applications. The obtained $d_{\mathrm{XRD}, \mathrm{A}}$ are in relatively good agreement with BET $\left(d_{\mathrm{BET}}\right)$ and TEM $\left(d_{\mathrm{TEM}}\right)$ measurements. TEM measured average particle size $\left(d_{\mathrm{TEM}}\right)$ and geometric standard deviation $\left(\sigma_{\mathrm{g}}\right)$ of $\mathrm{TiO}_{2}$ with $0.1,5$ and 15 at. $\% \mathrm{Nb}$ were calculated based on TEM images, Fig. $2 \mathrm{a}, \mathrm{c}$ and e. $d_{\mathrm{TEM}}$ and $\sigma_{\mathrm{g}}$ were derived from log-probability plots. Particle size distribution curves are presented in Fig. 4, and calculated $\sigma_{\mathrm{g}}$ values between 1.5 and 1.7 are slightly larger than common flamederived particle size distribution (PSD). It is probably due to usage of $\mathrm{NbCl}_{5}$, an inorganic salt which is nonvolatile and leads to a broadening of the PSD (Messing et al. 1993). To explain the small discrepancy between $d_{\mathrm{XRD}}, d_{\mathrm{BET}}$ and $d_{\mathrm{TEM}}$ values, it should be noticed that a secondary rutile phase is present in the samples, which was not taken into account for $d_{\mathrm{XRD}}$ evaluation. Moreover, one should consider that all methods of particle size determination are based on different assumptions, and in the case of X-ray diffraction, the average crystallite size is obtained and not the particle size, as for BET or TEM.

\section{Optical properties of $\mathrm{TiO}_{2}: \mathrm{Nb}$ nanopowders}

Evaluation of optical properties of the photocatalyst is of a great importance. The band gap energy of such a material determines the range of irradiation under which the photocatalyst can be

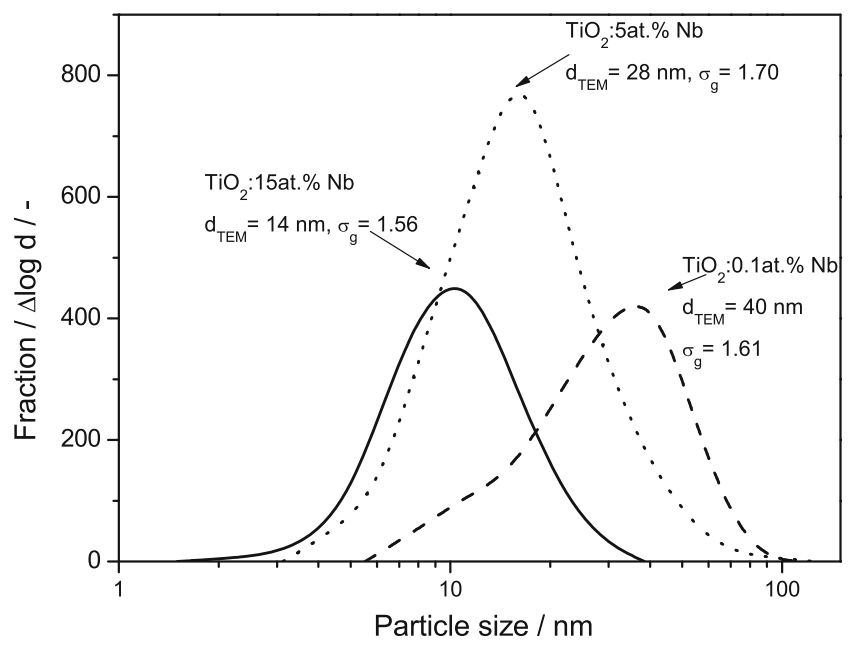

Fig. 4 Particle size distribution of $\mathrm{TiO}_{2}$ with $0.1,5$ and 15 at. $\% \mathrm{Nb}$ nanopowders calculated from TEM images 
efficiently applied. Therefore, it is crucial to investigate optical properties and resulting optical transitions in flame-made $\mathrm{TiO}_{2}: \mathrm{Nb}$ nanopowders especially because contradicting reports regarding the effect of $\mathrm{Nb}$ on the optical properties of $\mathrm{TiO}_{2}$ can be found in literature. Wang et al. (1995) reported a band gap shift from $3.03 \mathrm{eV}$ for $\mathrm{TiO}_{2}$ to $2.9 \mathrm{eV}$ for $\mathrm{TiO}_{2}: 0.5 \mathrm{~mol} \% \mathrm{Nb}$, where the given $\mathrm{TiO}_{2}$ band gap is a literature value and the one for $\mathrm{TiO}_{2}: 0.5 \mathrm{~mol} \% \mathrm{Nb}$ is an experimental one. Similarly, Mattsson et al. (2006) reported about the red shift of the fundamental absorption edge from $394 \mathrm{~nm}(3.15 \mathrm{eV})$ for undoped $\mathrm{TiO}_{2}$ to $411 \mathrm{~nm}(3.02 \mathrm{eV})$ for 20 at. $\%$ of $\mathrm{Nb}$ doping. In contrast to this, Gautron et al. (1983) reported no band shift for $\mathrm{TiO}_{2}-\mathrm{NbO}_{2}$ solid-state solution with 20 at. $\% \mathrm{Nb}$.

Diffuse reflectance spectroscopy was used to evaluate the optical properties and the band gap of flame-made $\mathrm{TiO}_{2}: \mathrm{Nb}$ nanopowders. The increase of $\mathrm{Nb}$ concentration decreases the diffuse reflectance $\left(R_{\text {diff }}\right)$ in the visible range, which indicates improved light absorption in this range (Fig. 5). In $\mathrm{TiO}_{2}$ with low doping level from 0.1 to 1 at. $\% \mathrm{Nb}$, a strong reduction of $R_{\text {diff }}$ intensity is observed in the range of 500-800 nm and a moderate one in the fundamental absorption region (Fig. 5a). For $\mathrm{TiO}_{2}: 5$ at.\% $\mathrm{Nb}$ nanopowder, the

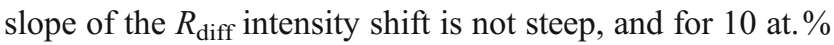
$\mathrm{Nb}$, it reaches a plateau which is again shifted to lower intensity for 15 at.\% $\mathrm{Nb}$ (Fig. $5 \mathrm{~b}$ ). The difference of $R_{\text {diff }}$ for $\mathrm{TiO}_{2}$ with lower (0.1-1 at.\%) and higher (5-15 at.\%) niobium content can be related to the presence of secondary phase. In flame-made $\mathrm{TiO}_{2}$ nanopowders, the solubility limit was exceeded for $\mathrm{Nb}$ level $>1$ at.\%. This means that up to 1 at.\% $\mathrm{Nb}$, no $\mathrm{Nb}$-related secondary phase was detected, and it can be assumed that $\mathrm{Nb}^{5+}$ substitutes $\mathrm{Ti}^{4+}$. In case of 5 at. $\%$ or higher $\mathrm{Nb}$ concentration, the material is heterogeneous, and the additional electron transitions can occur due to this fact. $\mathrm{Nb}_{2} \mathrm{O}_{5}$ is present most probably on the $\mathrm{TiO}_{2}$ surface and therefore lowers $R_{\text {diff }}$ intensity. The particle size is an another factor which can have an influence on the different trend of $\mathrm{TiO}_{2}: \mathrm{Nb}$ with low and with high dopant level. As already mentioned (Table 1), nanopowders with the $0.1-1$ at. $\% \mathrm{Nb}$ doping level have a comparable particle size $(\sim 35 \mathrm{~nm})$, and therefore, the main effect of the enhanced light absorption in the visible range can be assigned to the increased $\mathrm{Nb}$ level. In case of $\mathrm{TiO}_{2}$ with higher doping levels, the increased level of niobium doping is followed by the reduction of the particle size $\left(d_{\mathrm{BET}}\right)$ from $24 \mathrm{~nm}$ for $\mathrm{TiO}_{2}: 5$ at. $\% \mathrm{Nb}$ to $18 \mathrm{~nm}$ for $\mathrm{TiO}_{2}: 15$ at.\% $\mathrm{Nb}$. This results in more surface-related defects and can also cause the change in the $R_{\text {diff }}$ spectra.

The band gap energy $\left(E_{\mathrm{g}}\right)$ and the doping-related electronic transitions were evaluated from the peak maximum of the differential reflectance spectra $\left(\mathrm{dR}_{\mathrm{diff}}\right)$ vs. wavelength (Fig. 6). This is the most appropriate method of the band gap estimation for well-crystalline semiconductor materials (Radecka et al. 2006; Michalow et al. 2009b). For the
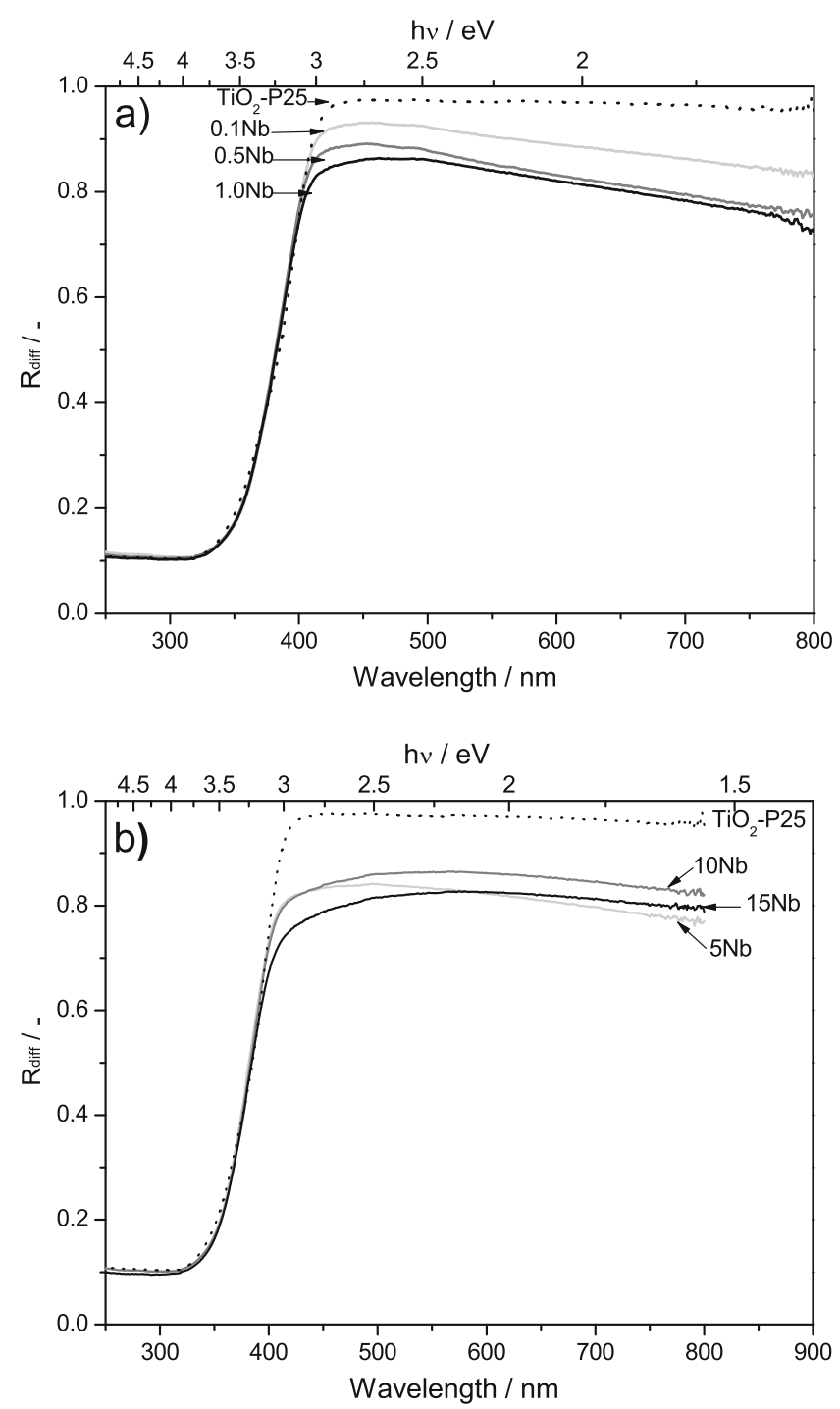

Fig. 5 Diffuse reflectance spectra a of $\mathrm{TiO}_{2}$ doped with $0.1,0.5$ and 1 at. $\% \mathrm{Nb}$ and $\mathbf{b}$ of $\mathrm{TiO}_{2}$ doped with 5,10 and 15 at.\% $\mathrm{Nb}$ nanopowders compared with $\mathrm{TiO}_{2}-\mathrm{P} 25$ nanopowder

commercial $\mathrm{TiO}_{2}-\mathrm{P} 25$ (Fig. 6a), differential reflectance spectrum was fitted with two Gaussian plots $E_{\mathrm{g} 2}=3.31 \mathrm{eV}$ and $E_{\mathrm{g} 3}=3.11 \mathrm{eV}$, which can be assigned to the electronic transition in the anatase and rutile phase, respectively (Table 2). Beside the peaks related to the anatase $\left(E_{\mathrm{g} 2}\right)$ and rutile $\left(E_{\mathrm{g} 3}\right)$ phase, a third $E_{\mathrm{g} 1}$ can be distinguished at shorter wavelengths from the $\mathrm{TiO}_{2}-\mathrm{FSS} \mathrm{dR}_{\text {diff }}$ spectra (Fig. 6b). The electronic transition at $E_{\mathrm{g} 1}$ is derived from the amorphous phase, which is slightly shifted to a higher energy and can be present in asprepared samples due their high surface area (Tian et al. 2005; Ohtani et al. 1997). As can be seen on Fig. 6c, d, niobium doping in $\mathrm{TiO}_{2}$ caused an appearance of an additional electronic transition $E_{\mathrm{g} 4}$ around $2.8 \mathrm{eV}$ (Table 2), beside already assigned $E_{\mathrm{g} 1}, E_{\mathrm{g} 2}$ and $E_{\mathrm{g} 3}$. Mulmi et al. (2004) revealed also an additional absorption band at $2.2 \mathrm{eV}$ in $\mathrm{Nb}$-doped anatase single crystal. This additional absorption was explained by a 

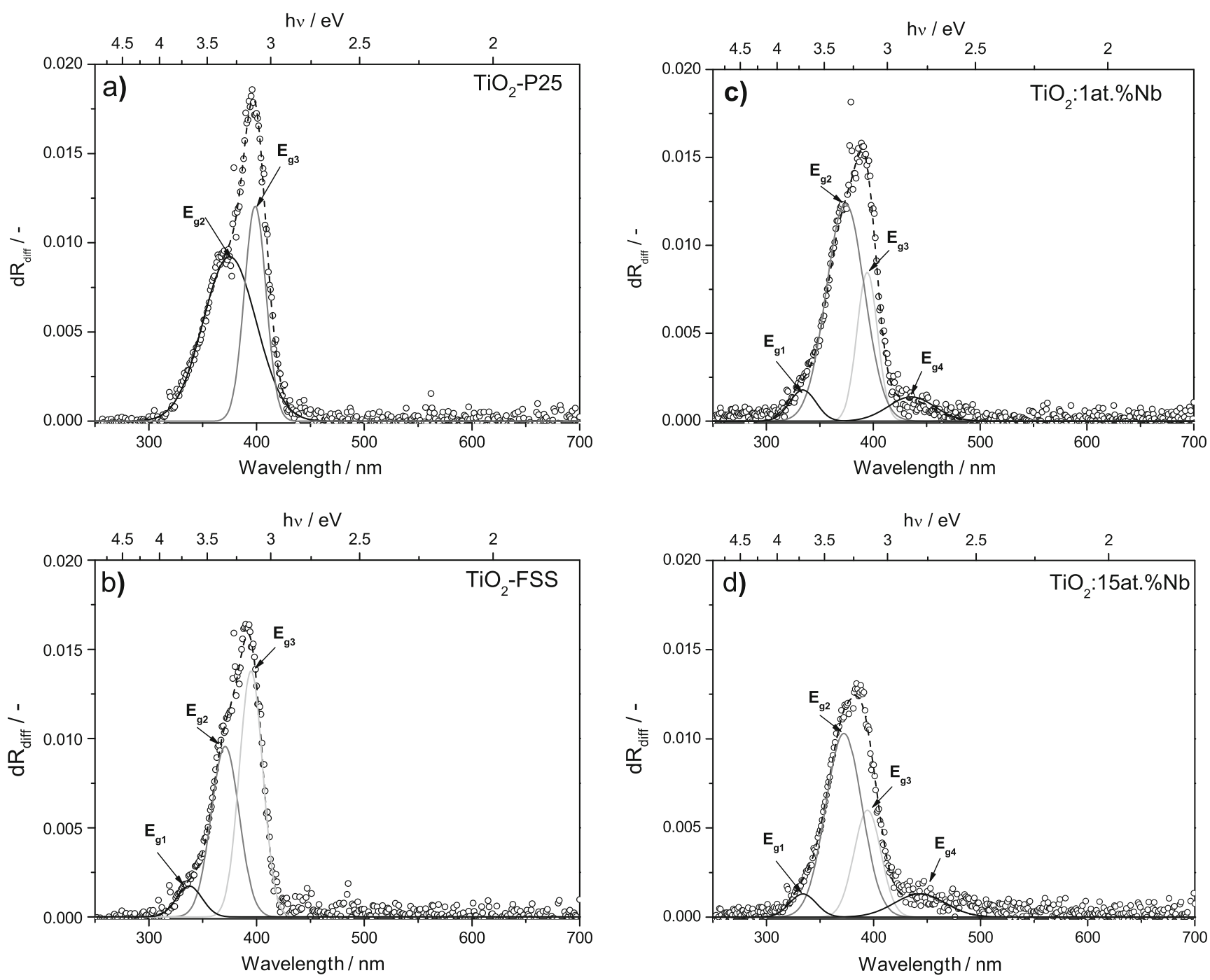

Fig. 6 The differential reflectance spectra of $\mathbf{a ~} \mathrm{TiO}_{2} / \mathrm{P} 25$, b $\mathrm{TiO}_{2}-\mathrm{FSS}$, c $\mathrm{TiO}_{2}: 1$ at. $\% \mathrm{Nb}$ and $\mathbf{d ~} \mathrm{TiO}_{2}: 15$ at.\% $\mathrm{Nb}$ nanopowders vs. wavelength and energy fitted by Gaussian plots, where $E_{g 1}, E_{g 2}, E_{g 3}$ and $E_{g 4}$

d-d transition in the conduction band. With increased level of niobium, a slight shift of the dopant-related transitions towards longer wavelengths was observed. Since $\mathrm{Nb}^{5+}$ is a donor type of dopant, it can be assumed that the dopant-related level is located under the conduction band within the band gap. Each

Table 2 Transition energy levels of $\mathrm{TiO}_{2}: \mathrm{Nb}$ and $\mathrm{TiO}_{2}-\mathrm{P} 25$ nanopowders

\begin{tabular}{lllll}
\hline Sample name & $E_{\mathrm{g} 1} / \mathrm{eV}$ & $E_{\mathrm{g} 2} / \mathrm{eV}$ & $E_{\mathrm{g} 3} / \mathrm{eV}$ & $E_{\mathrm{g} 4} / \mathrm{eV}$ \\
\hline $\mathrm{TiO}_{2}-\mathrm{P} 25$ & - & 3.31 & 3.11 & - \\
$\mathrm{TiO}_{2}: 0.1$ at. $\% \mathrm{Nb}$ & 3.75 & 3.31 & 3.12 & 2.87 \\
$\mathrm{TiO}_{2}: 0.5$ at. $\% \mathrm{Nb}$ & 3.71 & 3.32 & 3.13 & 2.87 \\
$\mathrm{TiO}_{2}: 1$ at. $\% \mathrm{Nb}$ & 3.71 & 3.32 & 3.14 & 2.85 \\
$\mathrm{TiO}_{2}: 5$ at.\% $\mathrm{Nb}$ & 3.71 & 3.32 & 3.14 & 2.83 \\
$\mathrm{TiO}_{2}: 10$ at.\% $\mathrm{Nb}$ & 3.71 & 3.32 & 3.14 & 2.81 \\
$\mathrm{TiO}_{2}: 15$ at.\% $\mathrm{Nb}$ & 3.71 & 3.33 & 3.14 & 2.80 \\
\hline
\end{tabular}

indicate transition energy for amorphous $\mathrm{TiO}_{2}$, anatase phase, rutile phase and doping, respectively

applied doping level of niobium affected the electronic structure of $\mathrm{TiO}_{2}$. According to literature (Stone and Davis 1998), it was not possible to distinguish the $\mathrm{Nb}_{2} \mathrm{O}_{5}$-related electronic transition, which is located at around $3.3 \mathrm{eV}$ in $\mathrm{TiO}_{2}: \mathrm{Nb}$ nanopowders with $\mathrm{Nb}>1$ at.\%. There are also no reports about such observation even for samples up to 20 at.\% $\mathrm{Nb}$ of doping (Mattsson et al. 2006). As can be seen from Fig. 6c, d, the overall intensity of the differential spectra lowers with increased $\mathrm{Nb}$ concentration. It is probably related to the increased number of defects with higher $\mathrm{Nb}$ content as well as increased number of surface-related defects since the particles size changes from $35 \mathrm{~nm}$ for $\mathrm{TiO}_{2}: 1$ at. $\% \mathrm{Nb}$ to $18 \mathrm{~nm}$ for $\mathrm{TiO}_{2}: 15$ at. $\% \mathrm{Nb}$. On the other hand, the relative intensity of transition at $\sim 2.8 \mathrm{eV}$ is slightly higher for higher doping. However, it should not be taken as an absolute value since there are several other factors which can have an influence on the $\mathrm{dR}_{\text {diff }}$ intensity. 
Photocatalytic activity

The photocatalytic activity of flame-made $\mathrm{TiO}_{2}: \mathrm{Nb}$ nanopowders was evaluated under UVA and VIS irradiation. As model pollutants, methylene blue (MB), methyl orange (MO) and 4-chlorophenol (4-CP) were chosen.

Methylene blue (Lakshmi et al. 1995; Mills and Wang 1999; Houas et al. 2001; Awati et al. 2003) and methyl orange (Almquist and Biswas 2002; Sclafani and Herrmann 1996) are representatives of cationic and anionic type of pollutant. 4-Chlorophenol is an inert molecule with a benzene ring structure, which allows capture of the radical intermediates or the direct interaction with an electron (Mills et al. 1993; Mills and Morris 1993; Hoffmann et al. 1995; Linsebigler et al. 1995; Mills and Davies 1995; Guillard et al. 1999; Herrmann et al. 1999). Langmuir-Hinshelwood kinetic model was used to evaluate kinetics of the photocatalytic performance of $\mathrm{TiO}_{2}: \mathrm{Nb}$ nanopowders as a function of niobium concentration (Figs. 7 and 9) (Yang et al. 2005). The apparent first-order photodecomposition kinetic rate constant $\left(k_{\text {app }}\right)$ was calculated on the basis of $\ln \left(C / C_{0}\right)$ vs. time plots, which show a linear dependence. The slope of $\ln \left(C / C_{0}\right)$ vs. time allows to calculate the $k_{\text {app }}$ value. For $k_{\text {app }}$ calculation of photocatalytic performance under UVA irradiation, the first $15 \mathrm{~min}$ of the reaction was taken into account, while in the case of VIS irradiation, $180 \mathrm{~min}$ of the reaction was considered. Adsorption of the pollutant on the photocatalysts surface is an important step in photodecomposition processes (Fox and Dulay 1993). That is why the time (10 min) needed for adsorption of the pollutant on the surface of the photocatalysts was included in the evaluation of the photocatalytic kinetic rate. All the obtained photocatalytic results were compared to commercially available $\mathrm{TiO}_{2}-\mathrm{P} 25$ (Evonik Industries AG) nanopowder. $\mathrm{TiO}_{2}-\mathrm{P} 25$ became a research standard

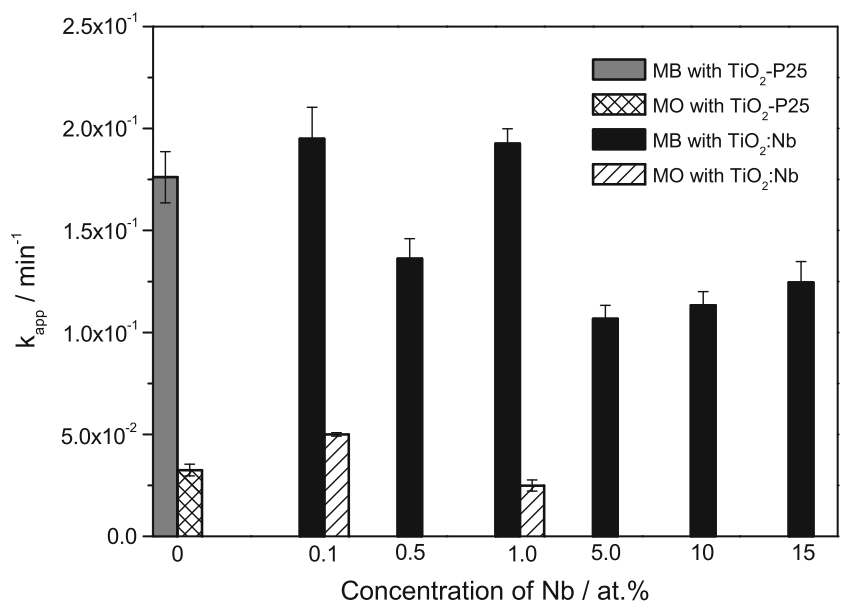

Fig. 7 Comparison of apparent first-order photodecomposition kinetic rate constant $\left(k_{\mathrm{app}}\right)$ of $\mathrm{MB}$ and $\mathrm{MO}$ under UVA irradiation in the presence of $\mathrm{TiO}_{2}: \mathrm{Nb}$ and $\mathrm{TiO}_{2}-\mathrm{P} 25$ as a reference

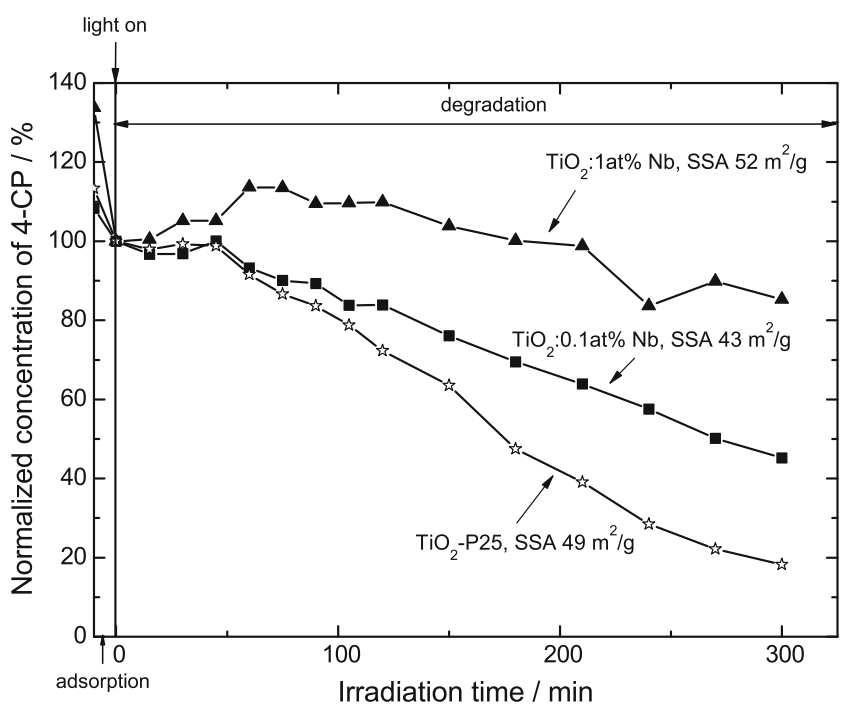

Fig. 8 Degradation of 4-CP with $\mathrm{TiO}_{2}: \mathrm{Nb}$ and $\mathrm{TiO}_{2}-\mathrm{P} 25$ under UVA irradiation. Negative time $(-10 \mathrm{~min})$ indicates the period of $4-\mathrm{CP}$ adsorption on the surface of photocatalyst

due to its reasonably well-defined nature (Table 1) and its high photoactivity in the UV range.

Figure 7 shows a photodecomposition of $\mathrm{MB}$ and $\mathrm{MO}$ in the presence of $\mathrm{TiO}_{2}: \mathrm{Nb}$ nanopowders under UVA irradiation. PCA of $\mathrm{TiO}_{2}: \mathrm{Nb}$ nanopowders for $\mathrm{MB}$ degradation was investigated over the whole range of niobium concentration. There is no clear trend of PCA with the niobium concentration. $\mathrm{TiO}_{2}: 5$ at. $\% \mathrm{Nb}$ nanopowder showed the lowest photocatalytic performance since it consists not only of anatase and rutile but also of a $\mathrm{Nb}_{2} \mathrm{O}_{5}$ phase. PCA rises when the niobium level is higher than 5 at.\%. This improved performance can be explained as follows: with higher $\mathrm{Nb}$ concentration, the specific surface area (SSA) increases and a particle size decreases (Fig. 1 and Table 1); therefore, photoinduced charges have a shorter path towards the

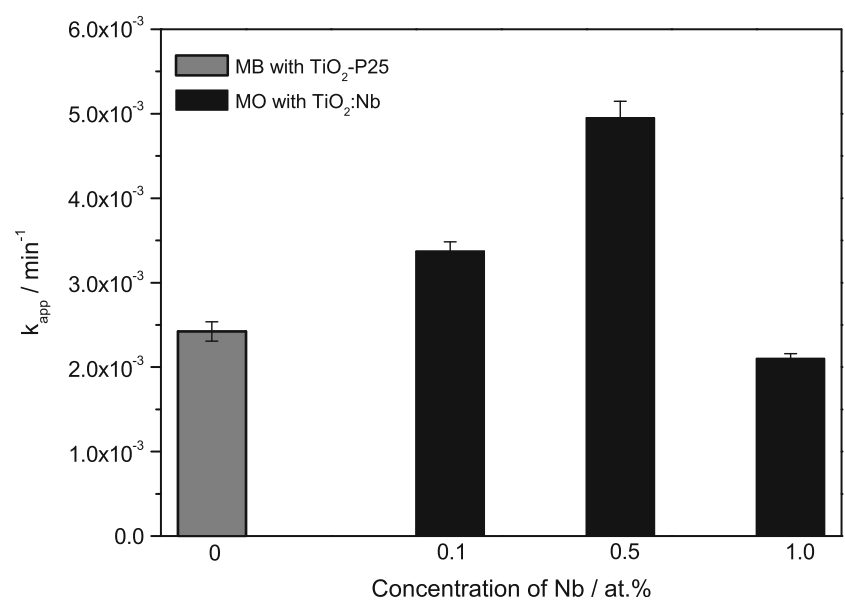

Fig. 9 Comparison of apparent first-order photodecomposition kinetic rate constant $\left(k_{\mathrm{app}}\right)$ of MB under VIS irradiation in the presence of $\mathrm{TiO}_{2}: \mathrm{Nb}$ and $\mathrm{TiO}_{2}-\mathrm{P} 25$ as a reference 
particle surface. High SSA means a high reactive surface towards both light absorption and pollutant adsorption. Another important factor is an increased dopant concentration and its effect on the defect creation, which can act both as active and recombination centres. $\mathrm{Nb}^{5+}$ acts as a donor type of dopant while substituting $\mathrm{Ti}^{4+}$ in the cationic sublattice. This requires a charge compensation to assure electroneutrality of the whole crystal. The most probable charge compensation mechanism for $\mathrm{TiO}_{2}$ doped with $\mathrm{Nb}<10$ at.\% is the formation of titanium vacancies (Sheppard et al. 2006), which is in accordance to the following $\mathrm{Nb}_{2} \mathrm{O}_{5}$ incorporation into $\mathrm{TiO}_{2}$ crystal lattice (Radecka and Rekas 1995):

$2 \mathrm{Nb}_{2} \mathrm{O}_{5} \leftrightarrow 4 \mathrm{Nb}_{\mathrm{Ti}}^{\cdot}+V_{\mathrm{Ti}}^{\prime \prime \prime \prime}+10 \mathrm{O}_{o}$

It was also reported (Nowotny et al. 2006) that titanium vacancies located at or near the surface are responsible for water adsorption and therefore for an improvement of photocatalytic performance. Hence, it can be concluded that titanium vacancies introduced by $\mathrm{Nb}^{5+}$ doping can act as active centres of hydroxyl radical formation. On the other hand, Finklea (1988) reported that $\mathrm{Nb}$ doping increases the charge carrier density. Charge compensation for donor doping in this case was achieved by electron localization on $\mathrm{Nb}^{4}$ ${ }^{+}$at $0.12 \mathrm{eV}$ below the conduction band, which can act as shallow traps and therefore as recombination centres. So, the electroneutrality condition assumes the form:

$$
\left[\mathrm{Nb}_{\mathrm{Ti}}\right]=4\left[V_{\mathrm{Ti}}^{\prime \prime \prime \prime}\right]+\left[e^{\prime}\right]
$$

Increased niobium content enhanced the surface acidity as was observed on the basis of improved adsorption of MB in darkness. From total MB concentration, 6.5 and $16.5 \%$ were adsorbed by $\mathrm{TiO}_{2}: 0.1$ at.\% $\mathrm{Nb}$ and $\mathrm{TiO}_{2}: 15$ at.\% $\mathrm{Nb}$, respectively, during equilibration time before the irradiation was switched on. In comparison, $\mathrm{TiO}_{2}-\mathrm{P} 25$ adsorbed $1.8 \%$ of the total $\mathrm{MB}$ amount under the same conditions. $\mathrm{TiO}_{2}: 0.1$ at. $\% \mathrm{Nb}$ and $\mathrm{TiO}_{2}: 1$ at. $\% \mathrm{Nb}$ nanopowders showed the best performance towards $\mathrm{MB}$ photodecomposition, even 1.11 times higher than $\mathrm{TiO}_{2}-\mathrm{P} 25$. Therefore, these two powders were chosen for further experiments towards photocatalytic decomposition of MO under UVA irradiation. As can be seen from Fig. 7, $\mathrm{TiO}_{2}: 0.1$ at.\% $\mathrm{Nb}$ shows also good PCA for another type of pollutant, and $k_{\text {app }}$ is 1.54 times higher than the one of $\mathrm{TiO}_{2}-\mathrm{P} 25$. However, pure $\mathrm{TiO}_{2}-\mathrm{P} 25$ shows better adsorbance of $\mathrm{MO}$ than any $\mathrm{TiO}_{2}: \mathrm{Nb}$ nanopowder. $\mathrm{TiO}_{2}-\mathrm{P} 25$ adsorbed $21.8 \%$ of total $\mathrm{MO}$ concentration, whereas $\mathrm{TiO}_{2}: 0.1$ at. $\% \mathrm{Nb}$ and $\mathrm{TiO}_{2}: 1$ at.\% $\mathrm{Nb}$ adsorbed 17.5 and $14.6 \%$, respectively. Based on these results, it can be concluded that both pollutants have different interaction with the surface of $\mathrm{TiO}_{2}: \mathrm{Nb}$ nanoparticles, which is related to the fact that $\mathrm{MB}$ is a cationic type of dye and MO is an anionic type of molecule. The apparent first-order kinetic rate constant for MO degradation is four times lower than the one for MB degradation in the presence of $\mathrm{TiO}_{2}: 0.1$ at. $\% \mathrm{Nb}$ under UVA irradiation. Therefore, for further experiments under UVA irradiation, 4-chlorophenol was chosen as a model inert molecule. $\mathrm{TiO}_{2}: 0.1$ at. $\% \mathrm{Nb}$ and $\mathrm{TiO}_{2}: 1$ at. $\% \mathrm{Nb}$ were selected due to their good activity under UVA irradiation. However, their performance is worse than of $\mathrm{TiO}_{2}-\mathrm{P} 25$. In case of $\mathrm{TiO}_{2}-\mathrm{P} 25$ and $5 \mathrm{~h}$ of irradiation, $18.3 \%$ of the total $4-\mathrm{CP}$ amount remained, while in case of $\mathrm{TiO}_{2}: 0.1$ at. $\% \mathrm{Nb}$, it was $45.2 \%$. On the left hand side of Fig. 8 , it can be seen that with an increased concentration of $\mathrm{Nb}$, the adsorption of 4-CP increased. For $\mathrm{TiO}_{2}: 1$ at. $\% \mathrm{Nb} 25.3 \%$ of total 4-CP concentration was left. Here, it has to be admitted that evaluation of 4-CP concentration by spectroscopic measurements was difficult due to the intermediate products which have an absorption in the range of 4-CP (Mills et al. 1993; Mills and Morris 1993).

In the next step, the photocatalytic performance of $\mathrm{TiO}_{2}: \mathrm{Nb}$ nanopowders with low $\mathrm{Nb}$ concentration towards $\mathrm{MB}$ and $\mathrm{MO}$ decomposition was tested under VIS irradiation $\left(\lambda_{\max }=435 \mathrm{~nm}\right) . \mathrm{TiO}_{2}: 0.1$ at. $\% \mathrm{Nb}$ and $\mathrm{TiO}_{2}: 0.5$ at. $\% \mathrm{Nb}$ showed higher performance than $\mathrm{TiO}_{2}-\mathrm{P} 25$ for MB decomposition. $\mathrm{TiO}_{2}: 0.5$ at. $\% \mathrm{Nb}$ performed even two times better than the commercial photocatalyst (Fig. 9). It is very interesting that the photocatalytic activity under VIS irradiation showed a reverse trend to the one under UVA irradiation if $\mathrm{TiO}_{2}$ nanopowders with low concentrations of $\mathrm{Nb}$ are used. None of the investigated materials showed a photocatalytic activity towards MO or 4-CP. Lack of photocatalytic activity towards MO decomposition under VIS irradiation can be explained by a lack of light available for photocatalyst excitation caused by full overlap of absorption spectra of MO with emission spectra of applied VIS irradiation. One should expect a high rate of dye photodecomposition through the photosensitized catalysis. However, this effect did not occur in the studied system. It can be explained by a non-proper location of the redox potential of $\mathrm{MO}^{*} / \mathrm{MO}^{-+}$with respect to the conduction band of photocatalyst. Therefore, transfer of the electron from an excited dye molecule to photocatalyst is not possible. In the case of 4-CP, a lack of activity of $\mathrm{TiO}_{2}: \mathrm{Nb}$ under VIS irradiation and low activity under UVA irradiation can be explained by a type of charge transfer in the investigated material.

To summarize, $\mathrm{TiO}_{2}: \mathrm{Nb}$ flame-made nanopowders with niobium concentration in the range from 0.1 to 1 at.\% showed better photocatalytic performance towards MB decomposition under UVA and VIS irradiation than $\mathrm{TiO}_{2}-\mathrm{P} 25$. Observed enhancement can be related not only to the preferable anatase structure of $\mathrm{TiO}_{2}: \mathrm{Nb}$ nanoparticles in comparison to $\mathrm{TiO}_{2}-\mathrm{P} 25$ but also to a good crystallinity and optimal spherical shape and size $(\sim 35 \mathrm{~nm})$ of the particles as well as to an improved surface acidity and therefore higher affinity towards water and hydroxyl groups adsorption due to the niobium doping (Onfroy et al. 2007; Akurati et al. 2008; Cui et al. 1995). The study of photocatalytic 
degradation of different types of pollutants like MB, MO and 4-CP representing cationic, anionic and inert type of molecules, respectively, by $\mathrm{TiO}_{2}: \mathrm{Nb}$ nanopowders showed that photocatalysis is a selective type of reaction, and not all types of pollutants interact in the same way with the photocatalyst surface. Further on, they do not follow the same degradation path and therefore show different degradation kinetics. These facts can be taken as an advantage when a selective type of photocatalyst is required.

Under VIS irradiation, $\mathrm{TiO}_{2}: 0.1$ at. $\% \mathrm{Nb}$ and $\mathrm{TiO}_{2}: 0.5$ at. $\%$ $\mathrm{Nb}$ showed a better performance towards MB decomposition than $\mathrm{TiO}_{2}-\mathrm{P} 25$. In all cases, decomposition of $\mathrm{MB}$ and $\mathrm{MO}$ was followed by a lowering of $\mathrm{pH}$, which indicates complete decomposition of MB and MO molecules and not only a decolorization process (Michalow et al. 2008). The good performance of $\mathrm{TiO}_{2}: \mathrm{Nb}$ nanopowder can be related to an improved electronic conductivity and an additional transition energy level located at $2.8 \mathrm{eV}$, which is directly irradiated by applied VIS irradiation. However, a question occurs as to why $\mathrm{TiO}_{2}-\mathrm{P} 25$ showed any photocatalytic performance towards MB degradation under VIS irradiation. It is probably due to the photosensitized type of the reaction, where MB dye molecule is photoexcited instead of the photocatalyst. An electron is transported from the photoexcited MB to the conduction band of a photocatalyst and reacts then, e.g. with $\mathrm{O}_{2}$ molecule, which is an electron scavenger, and a superoxide radical is created. These radicals can further react towards complete decomposition of MB. It seems that even a very small overlap of the adsorption spectra of MB and the applied irradiation is sufficient to drive the photosensitized type of reaction (Yan et al. 2006; Mills and Wang 1999). This can as well explain the lack of photocatalytic activity of investigated materials towards 4-CP decomposition under VIS irradiation. In case of colourless 4-CP molecule with an adsorption maximum at $280 \mathrm{~nm}$ the photosensitization reaction cannot occur.

\section{Conclusion}

$\mathrm{TiO}_{2}: \mathrm{Nb}$ nanoparticles were successfully obtained by liquidfed one-step flame spray synthesis. Obtained particles were spherically shaped and well crystalline. Up to 1 at. $\% \mathrm{Nb}$ nanopowder was composed mainly of anatase ( $96 \mathrm{wt} \%)$ and a small amount of rutile. Up from 5 at.\% of niobium formation of $\mathrm{Nb}_{2} \mathrm{O}_{5}$ phase was observed, which was homogenously dispersed on the $\mathrm{TiO}_{2}$ surface. Niobium doping caused a decrease of a diffuse reflectance intensity and introduced an additional transition level at $2.8 \mathrm{eV}$, which corresponds well to the assumption that niobium creates shallow electron traps below the conduction band. Such an analysis of optical spectra of $\mathrm{TiO}_{2}: \mathrm{Nb}$ is presented for the first time. Methylene blue, methyl orange and 4-chlorophenol were chosen as model molecules to investigate photocatalytic activity of $\mathrm{TiO}_{2}: \mathrm{Nb}$ nanopowders under UVA and VIS irradiation in suspension type of reactor. $\mathrm{TiO}_{2}: \mathrm{Nb}$ with $\mathrm{Nb}$ concentration up to 1 at.\% showed good photocatalytic performance towards MB decomposition under both types of irradiation, better than commercial $\mathrm{TiO}_{2}-\mathrm{P} 25$. MO could be decomposed only under UVA irradiation and $\mathrm{TiO}_{2}: 0.1$ at.\% was the best performing material composition under this type of irradiation. 4-CP was decomposed only under UVA irradiation, and $\mathrm{TiO}_{2}: \mathrm{Nb}$ nanopowders performed worse than $\mathrm{TiO}_{2}-\mathrm{P} 25$. An improved photocatalytic performance of $\mathrm{TiO}_{2}: \mathrm{Nb}$ is related to an improved light absorption in the visible range, $\mathrm{Nb}$-related defect structure and higher surface acidity. Under VIS light irradiation, a degradation of $\mathrm{MB}$ was probably driven by photosensitized type of excitation. $\mathrm{TiO}_{2}: \mathrm{Nb}$ is suggested as an efficient selective photocatalyst, which can be applied under solar irradiation because it showed an enhanced photocatalytic performance under UVA and VIS irradiation. However, due to the high photodegradation kinetic rates under UVA irradiation, the reaction is driven by the UVA part of the solar irradiation.

\section{References}

Akurati KK, Vital A, Dellemann J-P, Michalow K, Graule T, Ferri D, Baiker A (2008) Flame-made $\mathrm{WO}_{3} / \mathrm{TiO}_{2}$ nanoparticles: relation between surface acidity, structure and photocatalytic activity. Appl Catal, B 79:53-62

Almquist CB, Biswas P (2002) Role of synthesis method and particle size of nanostructured $\mathrm{TiO}_{2}$ on its photoactivity. J Catal 212:145156

Anukunprasert T, Saiwan C, Traversa E (2005) The development of gas sensor for carbon monoxide monitoring using nanostructure of $\mathrm{Nb}-\mathrm{TiO}_{2}$. Sci Technol Adv Mat 6:359-363

Asahi R, Morikawa T, Ohwaki T, Aoki K, Taga Y (2001) Visible-light photocatalysis in nitrogen-doped titanium oxides. Science 293:269271

Atashbar MZ, Sun HT, Gong B, Wlodarski W, Lamb R (1998) XPS study of $\mathrm{Nb}$-doped oxygen sensing $\mathrm{TiO}_{2}$ thin films prepared by sol-gel method. Thin Solid Film 326:238-244

Awati PS, Awate SV, Shah PP, Ramaswamy V (2003) Photocatalytic decomposition of methylene blue using nanocrystalline anatase titania prepared by ultrasonic technique. Catal Commun 4:393400

Borgarello E, Kiwi J, Grätzel M, Pellizetti E, Visca M (1982) Visible light induced water cleavage in colloidal solutions of chromiumdoped titanium dioxide particles. J Am Chem Soc 104:2996-3002

Carotta MC, Ferroni M, Gnani D, Guidi V, Merli M, Martinelli G, Casale MC, Notaro M (1999) Nanostructured pure and Nb-doped $\mathrm{TiO}_{2}$ as thick film gas sensors for environmental monitoring. Sens Actuators B 58:310-317

Chen X, Mao SS (2007) Titanium dioxide nanomaterials: synthesis, properties, modifications, and applications. Chem Rev 107:28912959

Cui H, Dwight K, Soled S, Wold A (1995) Surface acidity and photocatalytic activity of $\mathrm{Nb}_{2} \mathrm{O}_{5}$ photocatalysts. J Solid State Chem 115:187-191

Ferroni M, Carotta MC, Guidi V, Martinelli G, Ronconi F, Richard O, Van Dyck D, Van Landuyt J (2000) Structural characterization of $\mathrm{Nb}-\mathrm{TiO}_{2}$ nanosized thick-films for gas sensing application. Sens Actuators B 68:140-145 
Finklea HO (1988) Semiconductor electrodes. Elsevier, Amsterdam, pp 58-61

Fox MA, Dulay MT (1993) Heterogeneous photocatalysis. Chem Rev 93:341-357

Fujishima A, Zhang X (2006) Titanium dioxide photocatalysis: present situation and future approaches. C R Chim 9:750-760

Gautron J, Lemasson P, Poumelec B, Marucco J-F (1983) Photoelectrochemical study of $(\mathrm{Ti}, \mathrm{V}) \mathrm{O}_{2}$ and $(\mathrm{Ti}, \mathrm{Nb}) \mathrm{O}_{2}$ alloys. Sol Energ Mater 9:101-111

Guillard C, Disdier J, Herrmann J-M, Lehaut C, Chopin T, Malato S, Blanco J (1999) Comparison of various titania samples of industrial origin in the solar photocatalytic detoxification of water containing 4-chlorophenol. Catal Today 54:217-228

Herrmann J-M, Matos J, Disdier J, Guillard C, Laine J, Malato S, Blanco J (1999) Solar photocatalytic degradation of 4chlorophenol using the synergistic effect between titania and activated carbon in aqueous suspension. Catal Today 54:255-265

Hoffmann MR, Martin ST, Choi W, Bahnemann DW (1995) Environmental applications of semiconductor photocatalysis. Chem Rev 95:69-96

Houas A, Lachheb H, Ksibi M, Elaloui E, Guillard C, Herrmann J-M (2001) Photocatalytic degradation pathway of methylene blue in water. Appl Catal, B 31:145-157

Kubacka A, Colon G, Fernandez-Garcia M (2009) Cationic (V, Mo, $\mathrm{Nb}, \mathrm{W}$ ) doping of $\mathrm{TiO}_{2}$-anatase: a real alternative for visible lightdriven photocatalysts. Catal Today 143:286-292

Lakshmi S, Renganathan R, Fujita S (1995) Study on $\mathrm{TiO}_{2}$-mediated photocatalytic degradation of methylene blue. J Photochem Photobiol A 88:163-167

Linsebigler AL, Guangquan L, Yates JT (1995) Photocatalysis on $\mathrm{TiO}_{2}$ surface: principles, mechanism and selected results. Chem Rev 95:735-758

Mattsson A, Leideborg M, Larsson K, Westin G, Österlund L (2006) Adsorption and solar light decomposition of acetone on anatase $\mathrm{TiO}_{2}$ and niobium doped $\mathrm{TiO}_{2}$ thin films. J Phys Chem B 110:1210-1220

Messing GL, Zhang SC, Jayanthi GV (1993) Ceramic powder synthesis by spray pyrolysis. J Am Ceram Soc 76:2707-2726

Michalow K, Vital A, Heel A, Graule T, Reifler F, Ritter A, Zakrzewska $\mathrm{K}$, Rekas M (2008) Photocatalytic activity of W-doped $\mathrm{TiO}_{2}$ nanopowders. J Adv Oxid Technol 11:56-64

Michalow KA, Heel A, Vital A, Amberg M, Fortunato G, Kowalski K, Graule T, Rekas M (2009a) Effect of thermal treatment on the photocatalytic activity in visible light of $\mathrm{TiO}_{2}-\mathrm{W}$ flame spray synthesized nanopowders. Top Catal 52:1051-1059

Michalow KA, Logvinovich D, Weidenkaff A, Amberg M, Fortunato G, Heel A, Graule T, Rekas M (2009b) Synthesis, characterization and electronic structure of nitrogen-doped $\mathrm{TiO}_{2}$ nanopowder. Catal Today 144:7-12

Mills A, Davies R (1995) Activation energies in semiconductor photocatalysis for water purification: the 4-chlorophenol- $\mathrm{TiO}_{2}-\mathrm{O}_{2}$ photosystem. J Photochem Photobiol A 85:173-178

Mills A, Morris S (1993) Photomineralization of 4-chlorophenol sensitized by titanium dioxide: a study of the initial kinetics of carbon dioxide photogeneration. J Photochem Photobiol A 71:75-83

Mills A, Wang J (1999) Photobleaching of methylene blue sensitised by $\mathrm{TiO}_{2}$ : an ambiguous system? J Photochem Photobiol A 127:123-134

Mills A, Morris S, Davies R (1993) Photomineralization of 4chlorophenol sensitized by titanium dioxide: a study of the intermediates. J Photochem Photobiol A 70:183-191

Mulmi DD, Sekiya T, Kamiya N, Kurita S, Murakami Y, Kodaira T (2004) Optical and electric properties of Nb-doped anatase $\mathrm{TiO}_{2}$ single crystal. J Phys Chem Solid 65:1181-1185

Nowotny J, Bak T, Nowotny MK, Sheppard LR (2006) $\mathrm{TiO}_{2}$ surface active sites for water splitting. J Phys Chem B 110:18492
Ogawa H, Abe A, Nishikawa M, Hayakawa S (1981) Preparation of tin oxide films from ultrafine particles. J Electrochem Soc 128:685689

Ohtani B, Ogawa Y, Nishimoto S (1997) Photocatalytic activity of amorphous-anatase mixture of titanium(IV) oxide particles suspended in aqueous solutions. J Phys Chem B 101:37463752

Okazaki S, Okuyama $\mathrm{T}$ (1983) $\mathrm{Nb}_{2} \mathrm{O}_{5}$ supported on $\mathrm{TiO}_{2}$. Catalytic activity for reduction of $\mathrm{NO}$ with $\mathrm{NH}_{3}$. Bull Chem Soc Jpn $56: 2159-2160$

Onfroy T, Manoilova OV, Bukallah SB, Hercules DH, Clet G, Houalla M (2007) Surface structure and catalytic performance of niobium oxides supported on titania. Appl Catal A 316:184190

Radecka M, Rekas M (1995) The studies of high-temperature interaction of $\mathrm{Nb}-\mathrm{TiO}_{2}$ thin films with oxygen. J Phys Chem Solid 56:1031-1037

Radecka M, Rekas M, Zakrzewska K (2006) Titanium dioxide in photoelectrolysis of water. Trends Inorg Chem 9:81-126

Radecka M, Rekas KE, Zakrzewska K, Heel A, Michalow KA, Graule $\mathrm{T}$ (2010) $\mathrm{TiO}_{2}$-based nanopowders and thin films for photocatalytical application. J Nanosci Nanotechnol 10:1032-1042

Ruiz A, Dezanneau G, Arbiol J, Cornet A, Morante JR (2003) Study of the influence of $\mathrm{Nb}$ content and sintering temperature on $\mathrm{TiO}_{2}$ sensing films. Thin Solid Film 436:90-94

Sclafani A, Herrmann J-M (1996) Comparison of photoelectronic and photocatalytic activities of various anatase and rutile forms of titania in pure liquid organic phases and in aqueous solutions. $\mathrm{J}$ Phys Chem 100:13655-13661

Shannon RD (1976) Revised effective ionic radii and systematic studies of interatomic distances in halides and chalcogenides. Acta Cryst A 32:751-767

Sharma RK, Bhatnagar MC, Sharma GL (1998) Mechanism in $\mathrm{Nb}$ doped titania oxygen gas sensor. Sens Actuators B 46:194-201

Sheppard L, Bak T, Nowotny J, Sorrell CC, Kumar S, Gerson AR, Barnes MC, Ball C (2006) Effect of niobium on the structure of titanium dioxide thin films. Thin Solid Film 510:119-124

Spurr RA, Myers H (1957) Quantitative analysis of anatase-rutile mixtures with an X-ray diffractometer. Anal Chem 29:760-762

Stone VF Jr, Davis RJ (1998) Synthesis, characterization, and photocatalytic activity of titania and niobia mesoporous molecular sieves. Chem Mater 10:1468-1474

Teleki A, Bjelobrk N, Pratsinis SE (2008) Flame-made Nb- and Cudoped $\mathrm{TiO}_{2}$ sensors for $\mathrm{CO}$ and ethanol. Sens Actuators B130:449-457

Tian G-L, He H-B, Shao J-D (2005) Effect of microstructure of $\mathrm{TiO}_{2}$ thin film on optical band gap energy. Chin Phys Lett 22:17871789

Traversa E, Di Vona ML, Licoccia S, Sacerdoti M, Carotta MC, Crema L, Martinelli G (2001) Sol-gel processed $\mathrm{TiO}_{2}$-based nano-sized powders for use in thick-film gas sensors for atmospheric pollutant monitoring. J Sol- Gel Sci Technol 22:167-179

Trenczek-Zajac A, Rekas M (2006) Electrical properties of Nb-doped titanium dioxide $\mathrm{TiO}_{2}$ at room temperature. Mater Sci Poland 24:53-60

Trenczek-Zajac A, Radecka M, Rekas M (2007) Photoelectrochemical properties of $\mathrm{Nb}$-doped titanium dioxide. Physica B 399:55-59

Trenczek-Zajac A, Radecka M, Jasinski M, Michalow KA, Rekas M, Kusior E, Zakrzewska K, Heel A, Graule T, Kowalski K (2009) Influence of $\mathrm{Cr}$ on structural and optical properties of $\mathrm{TiO}_{2}: \mathrm{Cr}$ nanopowders prepared by flame spray synthesis (FSS). J Power Sources 194:104-111

Tsvetkov N, Larina L, Shevaleevskiy O, Tae Ahn B (2011a) Effect of $\mathrm{Nb}$ doping of $\mathrm{TiO}_{2}$ electrode on charge transport in dye-sensitized solar cells. J Electrochem Soc 158:B1281-B1285 
Tsvetkov N, Larina L, Shevaleevskiy O, Tae Ahn B (2011b) Electronic structure study of lightly $\mathrm{Nb}$-doped $\mathrm{TiO}_{2}$ electrode for dyesensitized solar cells. Energ Environ Sci 4:1480-1486

Wang MH, Guo RJ, Tso TL, Perng TP (1995) Effects of sintering on the photoelectrochemical properties of $\mathrm{Nb}$-doped $\mathrm{TiO}_{2}$ electrodes. Int J Hydrogen Energy 20:555-560

Yan X, Ohno T, Abe R, Ohtani B (2006) Is methylene blue an appropriate substrate for a photocatalytic activity test? A study with visible-light responsive titania. Chem Phys Lett 429:606-610
Yang Y, Wu Q, Hu C, Wang E (2005) Efficient degradation of the dye pollutants on nonporous polyoxotungstate-anatase composite under visible-light irradiation. J Mol Catal A 225:203-212

Zaitsev SV, Moon J, Takagi H, Awano M (2000) Preparation and characterization of nanocrystalline doped $\mathrm{TiO}_{2}$. Adv Powder Technol 11:211-220

Zakrzewska K, Radecka M, Rekas M (1997) Effect of Nb, Cr, Sn additions on gas sensing properties of $\mathrm{TiO}_{2}$ thin films. Thin Solid Film 310:161-166 